\title{
Evaluation of Exogenous Insulin Homoeostasis by the Artificial Pancreas in Insulin-Dependent Diabetes
}

\author{
J. Mirouze, J. L. Selam, T. C. Pham, and D. Cavadore \\ Clinique des Maladies Métaboliques et Endocriniennes, Hôpital Saint-Eloi, Montpellier, France
}

Summary. With the artificial pancreas used by the authors, insulin was delivered through a venous infusion and the rate of delivery was adjusted according to data provided by a continuous blood glucose monitor. After different trials we selected control algorithms integrating two parameters: instantaneous blood glucose concentration and increasing or decreasing patterns of blood glucose. A constant basal insulin infusion rate was added and improved the control of glycaemic excursions. Different parameters concerning exogenous insulin homoeostasis were determined. The delay to reach an insulin effect was $18 \pm 2 \mathrm{~min}$ and was shortened by a priming-dose at the beginning of the infusion. The" insulin effect remained for $28 \pm 2 \mathrm{~min}$ after the infusion had been stopped, but differences were noted in the morning ( $21 \pm 2 \mathrm{~min})$, in the afternoon (32 \pm $2 \mathrm{~min})$ and during the night $(25 \pm 3 \mathrm{~min})$. Insulin needs were evaluated during meals. Related to the amount of carbohydrates, the doses fell from 0.53 units $/ \mathrm{hr} / \mathrm{g}$ of carbohydrate for breakfast to 0.15 for dinner. From these data, it appears that the efficiency of exogenous insulin exhibits a circadian rhythm.

Key words: Insulin infusion, artificial betacell, artificial endocrine pancreas, control algorithms, continuous blood glucose measurement.

The artificial pancreas or external artificial beta cell corresponds to a device developed in order to reach better control of spontaneous or provoked glycaemic excursions. This aim can be achieved by using an insulin and/or glucose infusion adjusted to blood glucose levels as measured by rapid chemical determinations on continuous blood sampling. This technique has been successfully developed and previously described by a number of authors $[1,2,3,4$, $18,19,20,10,5,6]$. In the present work, we describe a new system and its quantitative evaluation in relation to exogenous insulin homoeostasis in insulin-dependent diabetics.

\section{Materials and Methods}

The artificial pancreas that we use consists of 3 subsystems (Fig. 1).

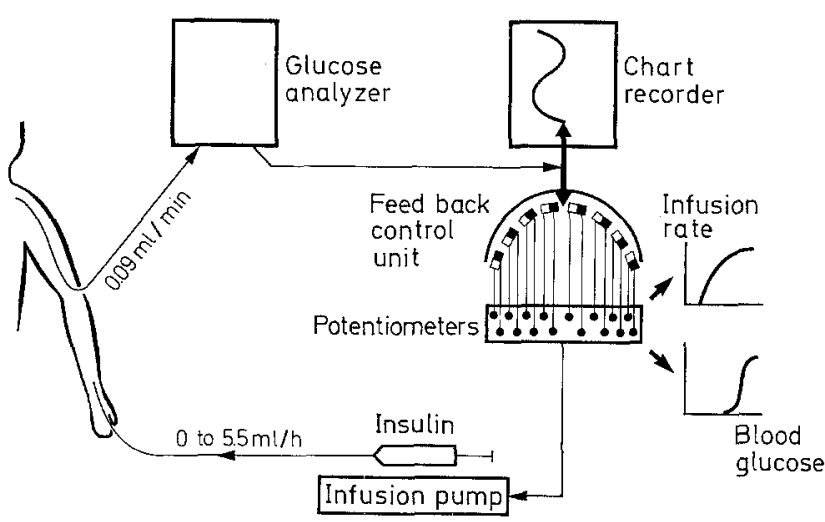

Fig. 1. Apparatus used for automated regulation of blood glucose. For description of the feed back control unit (right hand part of the figure), see Fig. 4

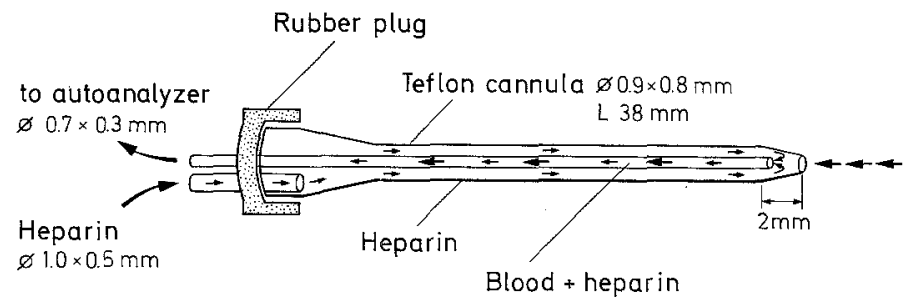

Fig. 2. Double lumen catheter for continuous blood sampling 


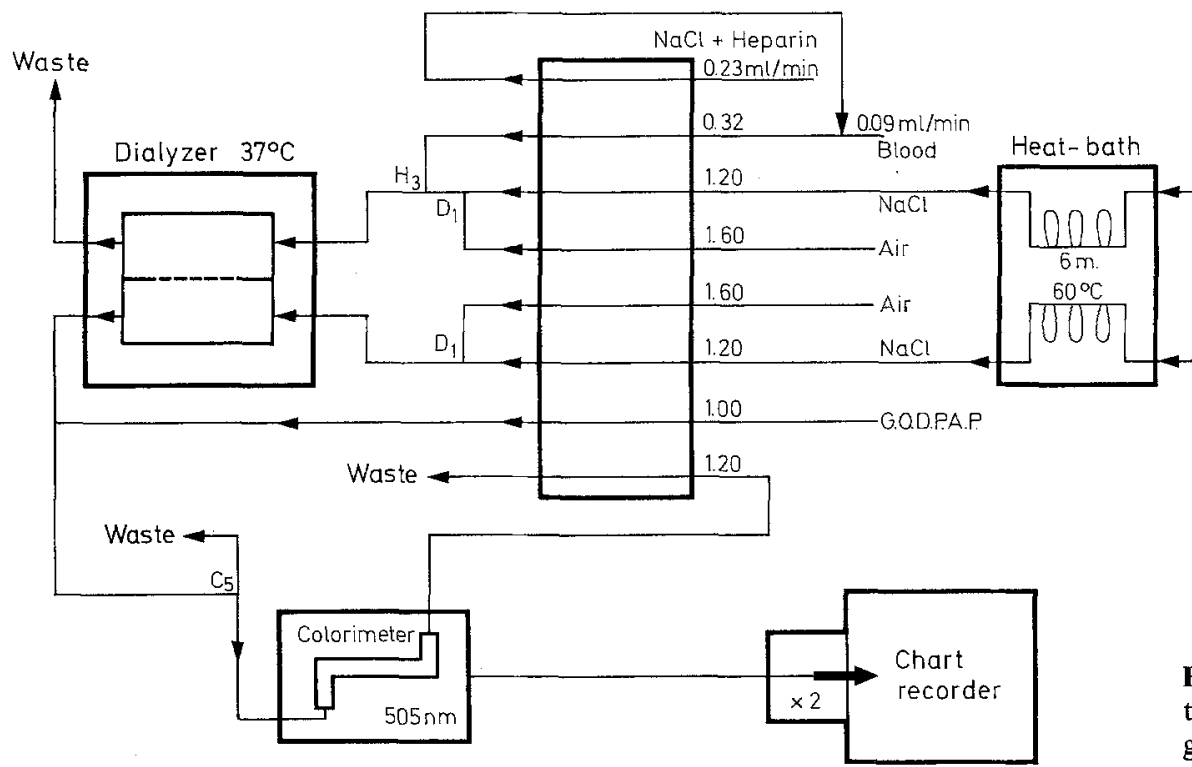

Fig. 3. Flow diagram used for rapid continuous measurement of whole blood glucose

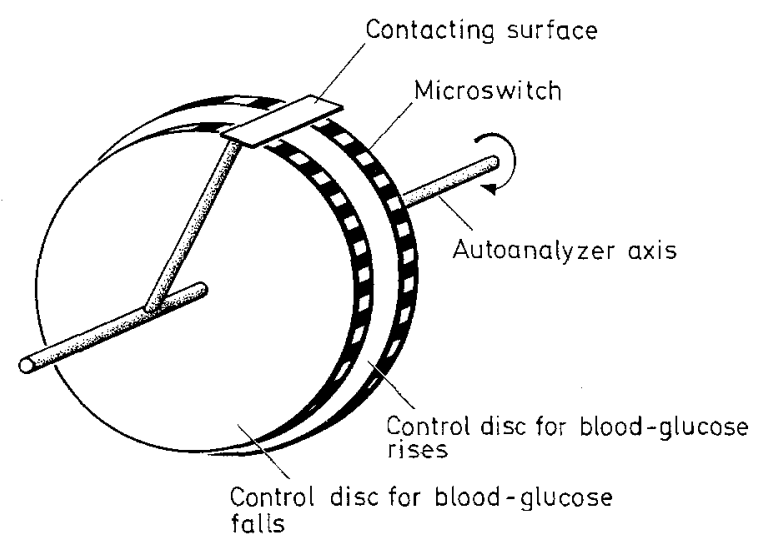

Fig. 4. Detail of the feed-back control unit used as an interface between blood glucose recording and insulin infusion unit

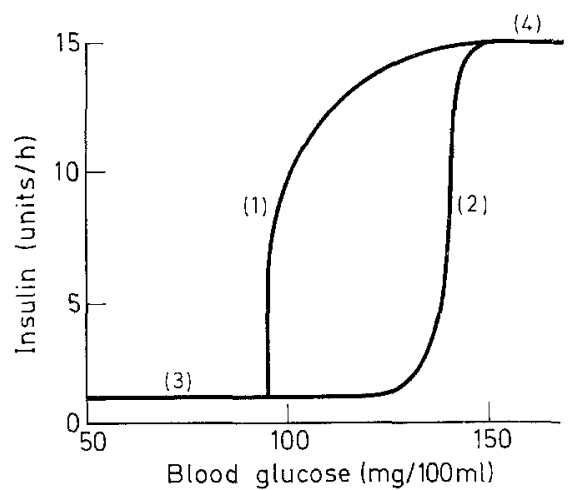

Fig. 5. Control algorithms relating insulin infusion and blood glucose. 1) control algorithms for blood glucose rises; 2) control algorithms for blood glucose falls; 3) basal insulin flow-rate $(0.25-1.5$ units $/ \mathrm{h})$; 4) maximum insulin flow-rate $(15$ units $/ \mathrm{h})$
1. the continuous blood glucose measurement,

2. the automatic adjustment system,

3. the insulin pump.

Blood samples were withdrawn through a double lumen catheter (Fig. 2). Into the outer lumen between the tubing and the cannula, heparin $(50 \mathrm{u} / \mathrm{ml}$ $0.154 \mathrm{~mol} / 1$ saline) was pumped at a rate of $0.23 \mathrm{ml} / \mathrm{min}$. The heparin when reaching the tip of the tube mixed with the blood entering the cannula and the blood-heparin mixture was pumped through the inner tube to the autoanalyzer at a rate of $0.32 \mathrm{ml} / \mathrm{min}$. The total blood loss amounted to $0.09 \mathrm{ml} / \mathrm{min}$, i. e. $129 \mathrm{ml} / 24 \mathrm{~h}$.

Continuous blood glucose measurement was achieved by means of a Technicon autoanalyzer using a modified glucose-oxidase method (G.O.DP.A.P. Boehringer) (Fig. 3). Routine recalibration after $12 \mathrm{~h}$ of continuous blood glucose analysis shows a small positive baseline drift of $0.5 \mathrm{mg}$ / $100 \mathrm{ml} / \mathrm{h}$ and no reduction in the sensivity of the calibration curve. The lag time between blood sampling and obtaining a blood glucose result was less than $3 \mathrm{~min}$, despite the presence of a 2 metre line between the patient and the measuring device. The presence of this long line allowed a certain amount of physical activity for the subject.

The insulin infusion was prepared by diluting Actrapid insulin (Novo 40 units per $\mathrm{ml}$ ) with saline to a final concentration of 2-4 units per $\mathrm{ml}$. It was delivered by a $50 \mathrm{ml}$ plastic syringe with the aid of a multispeed infusion pump (Sage model 240, range 0 to $5.5 \mathrm{ml} / \mathrm{hr}$ ). Albumin was not added because adsorption is negligible when insulin is present in relatively high concentrations in plastic syringes [17]. The mixture was infused into a superficial vein of 
Fig. 6. Continuous record of blood glucose (black)controlled by artificial pancreas (grey). Note absence of a constant basal insulin infusion

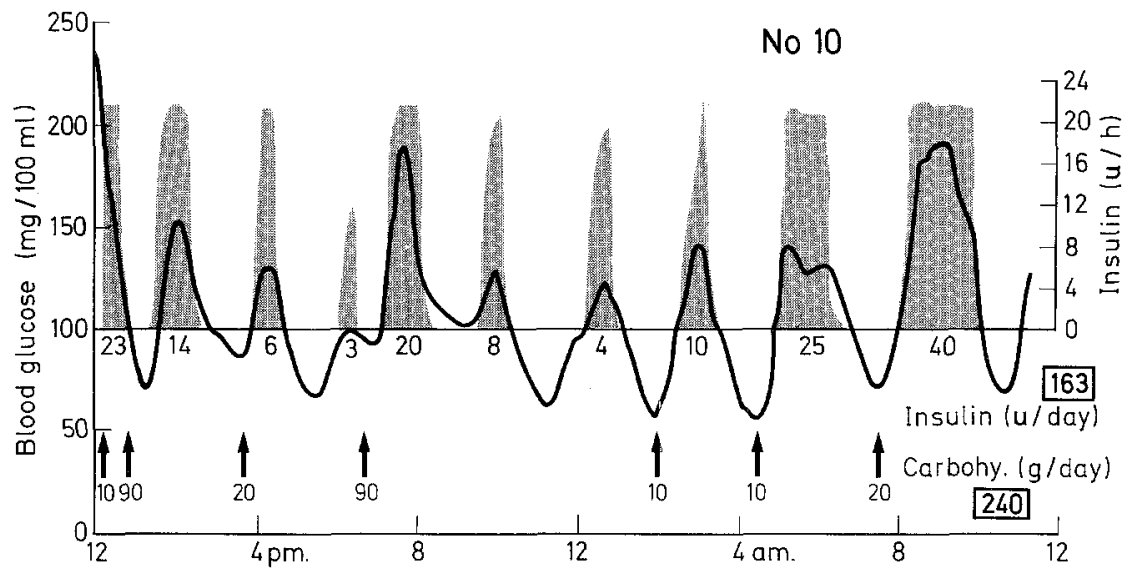

the forearm through an indwelling tube (diameter $5.5 \mathrm{~mm}$, length $200 \mathrm{~cm}$, Braun) fitted to a siliconed needle (Abbott).

The feed back control unit (Fig. 4) consisted of two series of microswitches located on two disks directly on the axis of the recorder. Each microswitch was connected to a preselected potentiometer which governs the rate of the pump. One of the discs was connected when blood glucose concentration rose, the other when blood glucose concentration fell. By this means, the system provided a range of infusion rates according to blood glucose concentration and increasing or decreasing pattern of blood glucose curve.

The control algorithms (Fig. 5) allowed a rapid response of insulin infusion, to a maximal rate when blood glucose rises. On the other hand, the infusion rate falls rapidly as soon as blood glucose begins to fall. A basal insulin infusion rate for low blood glucose concentrations was added subsequently.

\section{Patients}

Twenty insulin-dependent diabetics were studied over a 12 to $48 \mathrm{~h}$ period. During the day preceding the investigation, the patients were treated with 3 daily injections of regular insulin, in order to avoid any overlap between the insulin infusion on the day of investigation and the prolonged activity of lente insulin injected on the day before. Their main clinical characteristics are summarized in Table 1. None of the patients presented with degenerative or infectious disease.

\section{Results}

The time course of blood glucose recordings as adjusted by the artificial pancreas are shown on Figures 6,7 and 8 .
Table 1. Clinical data of patients studied with the artificial pancreas. $-N_{0} 1$ to 10 : without basal insulin flow rate; $N_{0} 11$ to 20 : with basal insulin flow rate

\begin{tabular}{|c|c|c|c|c|c|}
\hline 安 & 希 & 曾 & 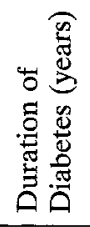 & 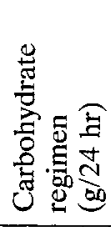 & 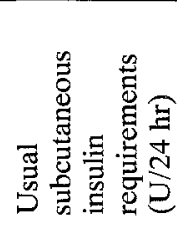 \\
\hline 1 & $\mathrm{M}$ & 26 & 3 & 160 & 67 \\
\hline 2 & $\mathrm{M}$ & 32 & 6 & 180 & 25 \\
\hline 3 & $\mathrm{~F}$ & 50 & 2 & 220 & 50 \\
\hline 4 & $\mathrm{~F}$ & 51 & 5 & 295 & 42 \\
\hline 5 & $\mathrm{M}$ & 33 & 9 & 220 & 25 \\
\hline 6 & $\mathbf{M}$ & 32 & 0.1 & 225 & 14 \\
\hline 7 & $\mathbf{M}$ & 42 & 10 & 270 & 41 \\
\hline 8 & $\mathrm{M}$ & 20 & 2 & 225 & 42 \\
\hline 9 & $\mathrm{M}$ & 25 & 0.1 & 250 & 30 \\
\hline 10 & $\mathbf{M}$ & 38 & 3 & 220 & 32 \\
\hline 11 & $\mathbf{M}$ & 18 & 0.3 & 295 & 85 \\
\hline 12 & $\mathbf{M}$ & 25 & 0.1 & 160 & 36 \\
\hline 13 & $\mathrm{~F}$ & 29 & 1 & 130 & 32 \\
\hline 14 & $\mathrm{~F}$ & 54 & 6 & 130 & 28 \\
\hline 15 & $\mathrm{~F}$ & 53 & 3 & 165 & 34 \\
\hline 16 & $\mathbf{M}$ & 28 & 10 & 280 & 67 \\
\hline 17 & $\mathrm{M}$ & 41 & 2 & 180 & 32 \\
\hline 18 & M & 14 & 2 & 250 & 63 \\
\hline 19 & $F$ & 14 & 0.1 & 200 & 42 \\
\hline 20 & $\mathbf{M}$ & 41 & 0.6 & 150 & 64 \\
\hline \multirow{2}{*}{\multicolumn{2}{|c|}{$\begin{array}{l}\text { Mean } \\
\pm \text { S.E.M }\end{array}$}} & 33 & 3.3 & 206 & 43 \\
\hline & & 3 & 0.7 & 11 & 4 \\
\hline
\end{tabular}

Figure 6 shows the results for a poorly controlled patient. Blood glucose concentrations varied from 55 to $195 \mathrm{mg} / 100 \mathrm{ml}$ during the infusion period. This could be considered satisfactory control but severe hyperglycaemic surges occurred throughout and the overall insulin requirement for the day was large. It should be noted that there was no basal insulin infusion in this case. By adding such a basal infusion, better control could be achieved in another difficult patient (Fig. 7). However, the basal rate ap- 

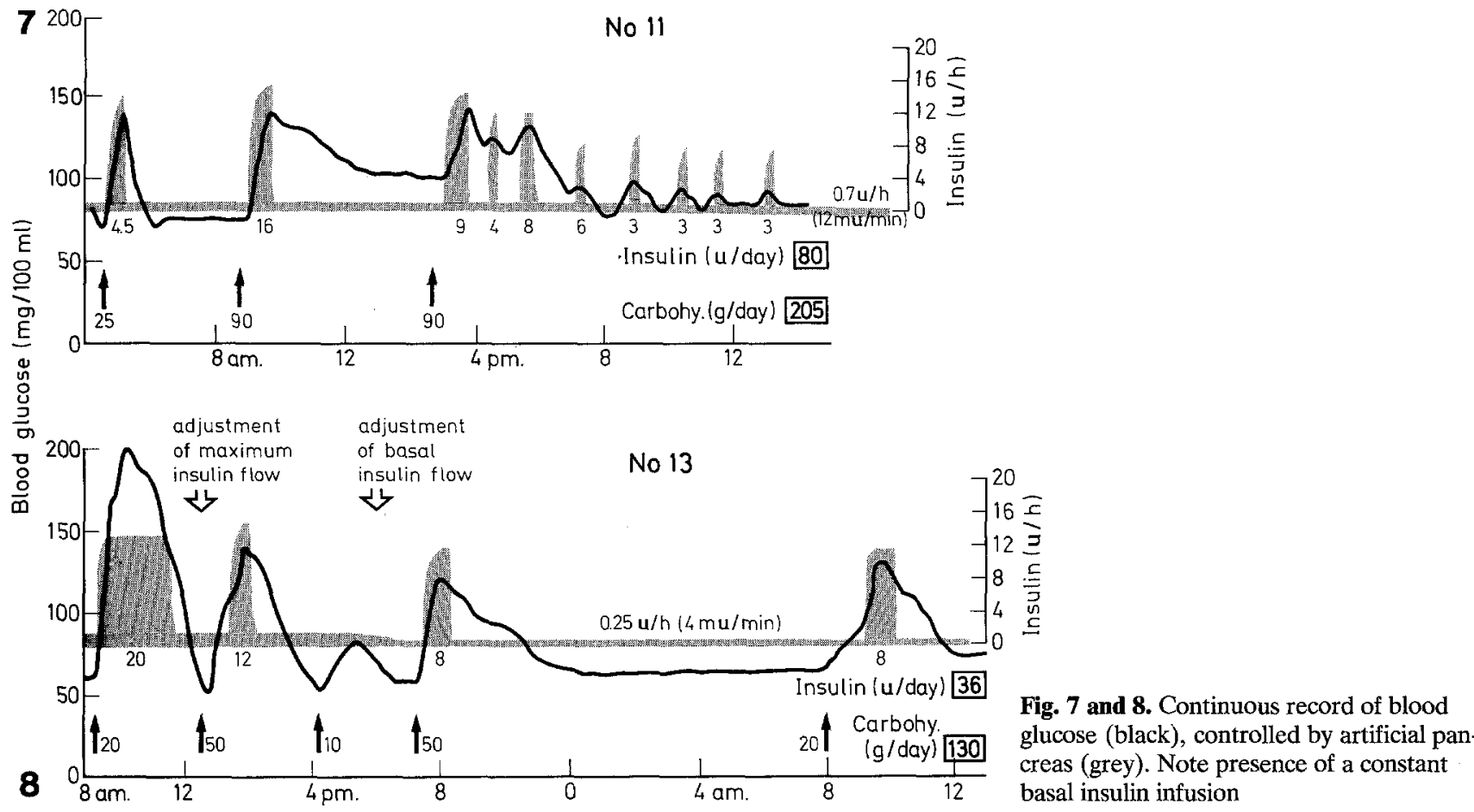

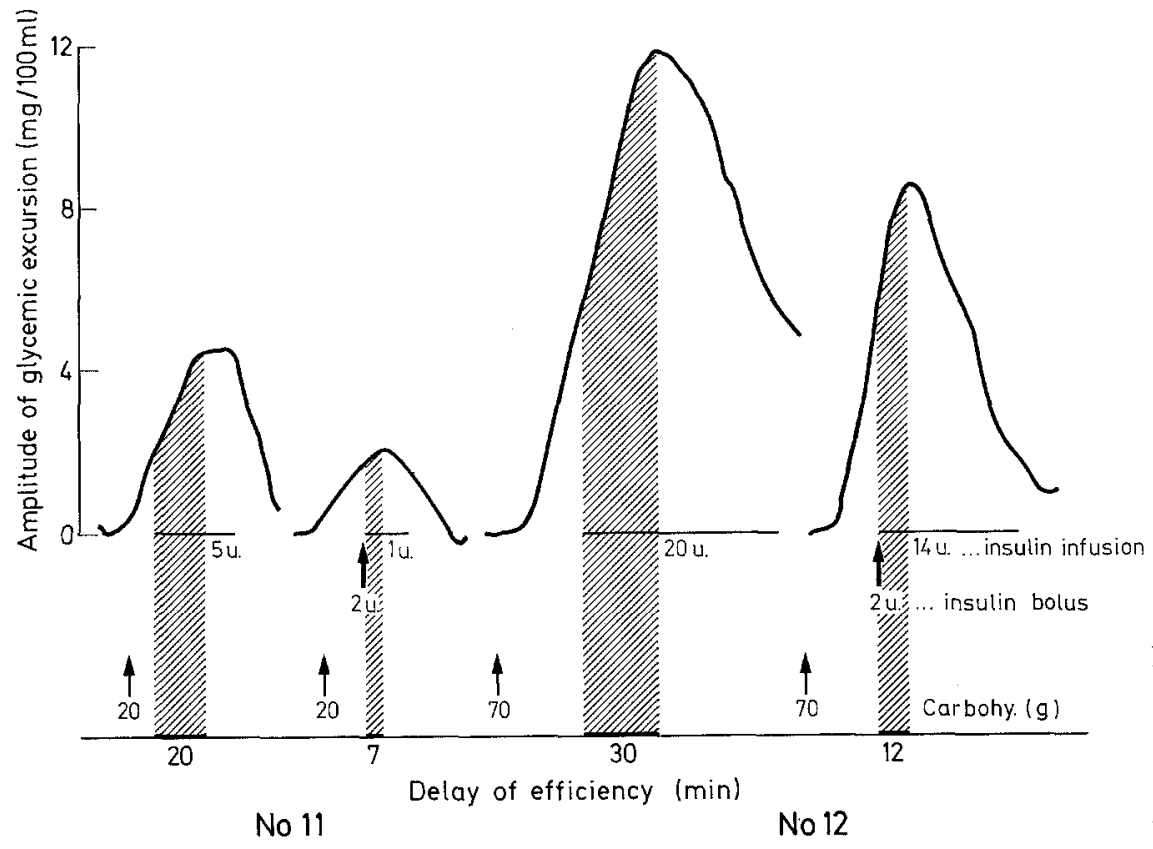

No 11 peared to be insufficient. This was probably responsible for small hyperglycaemic episodes immediately corrected by the modulated insulin infusion programme, but it resulted in an oscillating pattern of timecourse recording during the night. The controlled recording as shown in Figure 8 gives evidence that an accurate adjustment of basal and modulated infusion rates is required. Currently the dietary hyperglycaemic episodes are controlled by a maximal infusion rate of 15 units per hour. On the other hand, the basal infusion needs to be adjusted to each particular case and its value varies from 0.25 to 1.5 units per hour.

The delay to reach an insulin effect (i. e. the lagtime between the beginning of the infusion and discontinuation of spontaneous or meal induced blood glucose rises) was equal to $18 \pm 2 \mathrm{~min}$. In the absence of a priming dose the hypoglycaemic effect of 


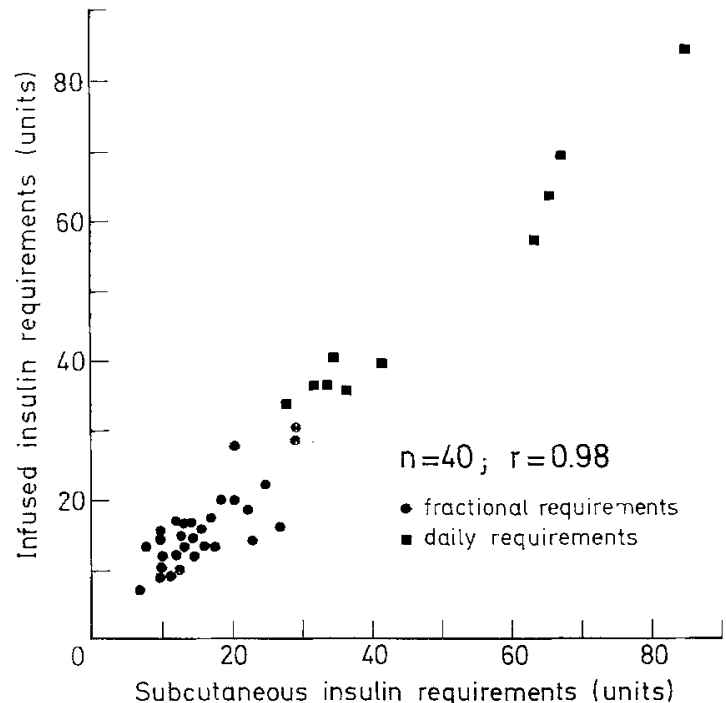

Fig. 10. Comparison between subcutaneous and infused insulin requirements

insulin was delayed when the infusion was started again. In Figure 9, this phenomenon is demonstrated in two cases (11 and 12) given similar carbohydrate loads $(20 \mathrm{~g}$ in case 11 and $70 \mathrm{~g}$ in case 12) without and with an IV bolus at the beginning of the insulin infusion.

The prolonged insulin effect (i. e. the lag-time between the end of the infusion and discontinuation of spontaneous or post hyperglycaemia blood glucose falls) was not dependent on the quantity of insulin previously infused and averaged $28 \pm 2$ min after the infusion had been stopped. However, differences were noted with the time of monitoring: 21 $\pm 3 \mathrm{~min}$ in the morning, $32 \pm 3 \mathrm{~min}$ in the afternoon, $25 \pm 3$ min during the night. The difference between the effect in the morning and in the afternoon was significant $(\mathrm{P}<0.01)$.

The exact evaluation of insulin requirements during infusion and subcutaneous treatment (Fig. 10) showed that at times of good control, a highly significant correlation existed between the subcutaneous and intravenous insulin doses needed ( $\mathrm{N}_{\mathrm{o}} 10$ to 20 ).

However the hourly insulin requirements were variable over the day. Their absolute values were slightly greater for breakfast than for lunch and dinner (Fig. 11). The doses remained in a similar range, but slightly lower, when a basal insulin infusion was added. The differences in insulin doses were more obvious when the number of units delivered was related to the amount of carbohydrates given: the doses fell from 0.53 unit per hour per $\mathrm{g}$ of carbohydrates for breakfast, to 0.15 for lunch and to 0.16 for dinner.

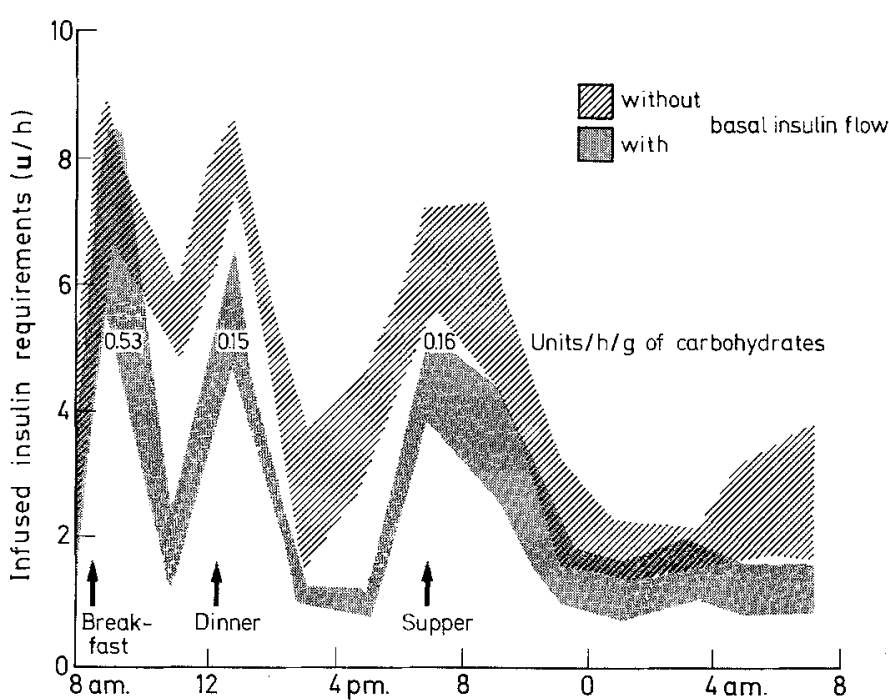

Fig. 11. Infused insulin requirements: diurnal variations

\section{Discussion}

Our artificial pancreas $[14,15]$ includes a continuous blood glucose recording controlling both a modulated and a basal insulin infusion flow rate, the latter maintaining a steady blood glucose between meals. These features are similar to some $[4,6,20]$ but not all [7] others. However our artificial pancreas differs from the others in the following:

- the information is transmitted to the infusion pump by a noncomputerized analog system.

- the computerization of the rate of blood glucose change (dynamic control) is replaced by two static control algorithms which regulate separately the increase and decrease of blood glucose concentration. The reliability of our system is confirmed by the excellent correlation ( $\mathrm{r}=0.98)$ between subcutaneous and infused insukin requirements (Fig. 10). Thus the artificial pancreas provides accurate information about the daily amounts of insulin required by the patient.

- hyperglycaemic substrate (glucagon or dextrose) is not added to the insulin infusion. Therefore the efficiency of the infused insulin can be easily analysed from the blood glucose curve.

Furthermore, the blood glucose recording and the insulin release are perfectly stable (Fig. 8) except for meal-induced peaks. This almost physiological pattern seems more difficult to reach with the double-infusion technique $[1,18]$

The delay in initial action $(18 \pm 2 \mathrm{~min})$ and discontinuation ( $28 \pm 2 \mathrm{~min}$ ) of effect of the infused insulin agrees with previous studies of the hormone half-life $[12,16,21,22]$. However, important differ- 
ences between patients were noted [12] making an adequate feed-back control quite difficult.

An IV bolus added at the beginning of any insulin infusion (Fig. 9) results in a more physiological profile [9] of the insulin release and improves the efficiency of the device.

Diurnal variations of insulin efficiency and/or requirements have been noted in normal and diabetic subjects $[8,11,13]$. In diabetics, diurnal analysis is difficult because of the intermittent and often inadequate insulin therapy. The artificial pancreas avoids this problem. Results show that the duration of effect of the infused insulin (which can be considered an index of the biological half-life) is significantly longer in the afternoon $(32 \pm 3 \mathrm{~min})$ than in the morning ( $21 \pm 3 \mathrm{~min})$. Furthermore, hourly insulin requirements per $\mathrm{g}$ of carbohydrate (Fig. 11) are much greater for breakfast $(0.53 \mu / \mathrm{hr} / \mathrm{g})$ than for lunch $(0.15 \mu / \mathrm{hr} / \mathrm{g})$ or dinner $(0.16 \mu / \mathrm{hr} / \mathrm{g})$ despite similar carbohydrate composition.

It appears from these results that this technique is of considerable value in evaluation of exogenous insulin homeostasis in insulin dependent diabetics.

\section{References}

1. Albisser, A.M., Leibel, B.S., Ewart, T.G., Davidovac, Z., Zingg, W.: The artificial pancreas. Diabetes 22, (Suppl. I) 294 (1973)

2. Albisser, A.M., Leibel, B.S., Ewart, T.G., Davidovac, Z., Botz, C.K., Zingg, W., Schipper, H., Gander, R.: Clinical control of diabetes by the artificial pancreas. Diabetes 23, 397-404 (1974)

3. Albisser, A.M., Leibel, B.S., Ewart, T.G., Davidovac, Z., Botz, C.K., Zingg, W.: An artificial endocrine pancreas. Diabetes 23, 389-396 (1974)

4. Albisser, A.M., Leibel, B.S., Marliss, E.B., Zinman, B., Botz, C.K., Zingg, W., Murray, F.T., Denoga, A.: Physiopathologie du diabète et pancréas endocrine artificiel. Journées de diabétologie de l'Hotel-Dieu, p. 259. Paris: Flammarion Ed. 1976

5. Clemens, A.H.: The artificial endocrine pancreas. A model system for computerized feedback control instrumentation. Miles Analecta 2, 4-8 (1975)

6. Clemens, A.H., Chang, P.H., Myers, R.W.: Le développement d'un système automatique d'infusion d'insuline contrôlé par la glycémie, son système de dosage du glucose et ses algorithmes de contrôle. Journées de diabétologie de l'Hotel Dieu, p. 269. Paris: Flammarion Ed. 1976

7. Deckert, T., Lorup, B.: Regulation of brittle diabetics by a preplanned insulin infusion program. Diabetologia 12, 573-579 (1976)

8. Gibson, T., Stimmler, L., Jarrett, R. J., Rutland, P., Shiu, M.: Diurnal variations in the effects of insulin on blood glucose plasma non esterified fatty acids and growth hormone. Diabetologia 11, 83-88 (1975)
9. Grodsky, G. M., Bennett, L.L., Smith, D.F., Schmid, F. G.: Effect of pulse administration of glucose or glucagon on insulin secretion in vitro. Metabolism 16, 222-223 (1967)

10. Kerner, W., Thum, Ch., Tamas, Jun G. Y., Beischer, W., Clemens, A. H., Pfeiffer, E.F.: Attempts at perfect normalization of glucose tolerance test of severe diabetics by artificial betacell. Horm. Metab. Res. 8, 256-261 (1976)

11. Malherbe, C., De Gasparo, M., De Hertogh, R., Hoet, J.J.: Circadian variations of blood sugar and plasma insulin levels in man. Diabetologia 5, 397-404 (1969)

12. Mirouze, J., Cartry, E., Jaffiol, C.: Analyse de la décroissance de la radioactivite plasmatique après injection d'insuline marquée dans le diabète suçré humain. Ass. Med. Lang. Franç. 3, 173-186 (1967)

13. Mirouze, J., Collard, F., Teisseire, J. P.: Analyse comparative en enregistrement continu des effects hyperglycemiants d'ingestions alimentaires prises à $8,12,16$ et 19 heures dans le diabète insuliné. Acta Diabetol. Lat. 9, 972-982 (1972)

14. Mirouze, J., Selam, J.L., Pham, T.C.: Infusion insulinique par débit asservi à l'enregistrement glycémique continu. Journées de Diabétologie de l'Hotel Dieu, p. 303. Paris: Flammarion Edition 1976)

15. Mirouze, J., Collard, F., Selam, J.L., Pham, T.C.: Continuous blood glucose monitoring in insulin treated diabetes. Horm. Metab. Res. (in press)

16. Ørskov, H., Christensen, N.J.: Plasma disappearance rate of injected human insulin in juvenile diabetic, maturity onset diabetic and non diabetic subjects. Diabetes 18, 653-659 (1969)

17. Page, M. McB, Alberti, K. G. M.M., Greenwood, R., Gumaa, K. A., Hockaday, T. D.R., Lowy, C., Nabarro, J.D. N., Pyke, D. A., Sonksen, P. H., Watkins, P.J., West, T.E. T.: Treatment of diabetic coma with continuous low dose infusion of insulin. Br. Med. J. 1974 II, 687-690

18. Pfeiffer, E. F., Thum, Ch, Clemens, A. H.: The artificial betacell. A continuous control of blood sugar by external regulation of insulin infusion (glucose controlled insulin infusion system). Horm. Metab. Res. 6, 339 (1974)

19. Pfeiffer, E.F., Thum, Ch, Beischer, W., Meissner, C., Tamas, Jr, G. Y., Clemens, A. H.: The artificial pancreas: application to experimental and clinical research. Abstracts of the 11th Annual Meeting of the E.A.S.D.) Diabetologia 11, 369 (1975)

20. Pfeiffer, E.F., Beischer, W., Thum, Ch., Clemens, A.H.: Le pancréas endocrine artificiel en clinique et en recherche. Journées de Diabétologie de l'Hotel-Dieu, p. 279. Paris: Flammarion Ed. 1976

21. Sönksen, P.H., Srivastava, M.C., Tompkins, C. V., Nabarro, J.D. N.: Growth hormone and cortisol response to insulin infusion in patients with diabetes mellitus. Lancet 1972 II, 155-159

22. Williams, R.F., Gleason, R.E., Soeldner, J.S.: The half-life of endogenous serum immunoreactive insulin in man. Metabolism 17, 1025-1029 (1968)

Received: November 2, 1976, and in revised form: March 1, 1977

Prof. J. Mirouze

Clinique des Maladies Métaboliques et Endocriniennes

Hôpital Saint-Eloi

F-34059 Montpellier Cedex

France 